\title{
El papel del protagonismo empresarial latinoamericano en la (re)construcción social de la categoría «inmigrante» en España
}

\section{Leonardo Cavalcanti}

Universitat Autònoma de Barcelona. Departament de Sociologia

08193 Bellaterra (Barcelona). Spain

leonardo.cavalcanti@uab.cat

\section{Resumen}

Este artículo analiza parte de los resultados del trabajo de campo que todavía está en curso - en el marco de la investigación de postdoctorado - sobre las iniciativas empresariales de los inmigrantes latinoamericanos en las ciudades de Madrid y Barcelona. A través de «lugares comunes» que conforman las experiencias comerciales y urbanas de los latinoamericanos en ambas ciudades, el texto procura reflexionar sobre diversos aspectos relacionados con el reciente protagonismo comercial y empresarial de los inmigrantes en España. Tres ejes: fuerza de trabajo, provisionalidad y problema social son analizados y relacionados con el papel que desempeña el empresariado inmigrante en la propia (re)construcción de la condición social del inmigrante en España.

Palabras clave: empresariado inmigrante, latinoamericano, España.

Abstract. The entrepreneurial role of Latin Americans in the social (re)construction of the «immigrant» category in Spain

This work analyzes part of the results of an investigation, carried out by the author, in the landmark of the postdoctoral research, on the commercial activities of the Latin American migrants in the cities of Barcelona and Madrid. Through the "common places» that form the commercial and urban experiences of the Latin Americans in both cities, the article seeks to reflect on diverse aspects related with the recent increase in these businesses in Spain. Three elements: labour force, being a "permanent temporary» and migrants as a social problem are analyzed and contrasted with other works that reflect on the entrepreneurial role of immigrants in the reconstruction of these the three variables and constraints that generally are imposed to the immigrants in Spain.

Key words: immigrant business, Latin America, Spain.

\section{Sumario}

España como país de destino para los migrantes latinoamericanos

La presencia del empresariado latinoamericano en España
El empresariado latino y su impacto en la (re)construcción social del inmigrante

Conclusión

Bibliografía 
Todas las cosas derechas mienten, murmuró con desprecio el enano. Toda verdad es curva, el tiempo mismo es un círculo.

(NietzsCHe. Asi habló Zaratustra)

Una de las cuestiones actuales que viene ocupando continuamente las principales pautas en las agendas de gobiernos y organismos internacionales es, sin duda, la temática de las migraciones. Si las movilidades humanas, como ya es sabido, son una constante a través de las páginas de la historia, en las últimas décadas, el fenómeno migratorio ha ganado un protagonismo singular en el escenario internacional. Según Massey (1998), la influencia de la llamada «economía postindustrial», a partir de los años setenta, y las importantes transformaciones geopolíticas de Occidente en el siglo XX, que fueron de diversas órdenes y en esferas distintas de la sociedad, también han cambiado de modo radical las imágenes y las ideas sobre la inmigración y el inmigrante.

Como un fenómeno propio de nuestro tiempo, la migración tiende a ser analizada a partir de definiciones antagónicas. Según Evans-Pritchard (1978), cuando determinado evento está más distante en el tiempo, por lo general, es concebido por todos los grupos humanos como situaciones más o menos resueltas, mientras que los más cercanos a la «temporalidad» presente permiten múltiples interpretaciones. En este sentido, Da Matta (1987) afirma que, en determinados acontecimientos distantes en el tiempo, hay una predominancia de interpretaciones académicas en contraste con interpretaciones políticas. El evento está más «frío», por utilizar un calificativo inventado por LéviStrauss (1970). Concomitantemente, un acontecimiento más próximo a nuestro tiempo se convierte en un hecho que aun se está desarrollando. Un episodio que todavía no ha agotado su impacto, un tema «caliente» — por parafrasear a Lévi-Strauss - que aún depende de múltiples acciones y lecturas diferenciadas.

Así, como un tema "caliente», el fenómeno de las migraciones internacionales está inserto en la reciente configuración mundial y requiere un modo de reflexión a partir de un proceso dialéctico, considerando que la migración pertenece tanto al tiempo de la sociedad de inmigración como a la de emigración. Sólo al realizar esa doble mirada, la del que está allí y aquí, que está doblemente presente y ausente, es que se puede entender y pensar la inmigración y al inmigrante (Sayad, 1998).

En nuestro tiempo, la presencia de inmigrantes latinoamericanos en el territorio español tiene, según Santamaría (2002), un carácter aparentemente definitivo. Como «autores» de cultura y no sólo como «portadores», los latinoamericanos también vienen apostando por un protagonismo en la estructura social española. De unos años a esta parte, las iniciativas emprendedoras de los migrantes latinoamericanos residentes en España han crecido y se han diver- 
sificado de manera muy significativa. A pesar de que las actividades se sitúan mayoritariamente en el ámbito de las microempresas (como es el caso del pequeño comercio, los bares, las agencias de viajes, las peluquerías, los locutorios, etc.), también encontramos una gran variedad de actividades, como diversas ONG, agencias de cooperación internacional, asociaciones culturales, espacios educativos, medios de comunicación social, entre otras.

Así, a partir de las experiencias empresariales de los inmigrantes latinoamericanos residentes en las ciudades de Madrid y Barcelona, el presente texto se propone profundizar sobre el papel que desempeña el empresariado latino en la (re)construcción social del inmigrante en España. A través de los «lugares comunes» que forman las experiencias comerciales y urbanas de los latinos en ambas ciudades, es posible reflexionar sobre las distintas formas que constituyen la inmigración como un fenómeno social. Aunque, en una primera parte, el presente trabajo contextualiza las relaciones migratorias entre España y América Latina, no se trata de describir o analizar la existencia de ciertos flujos migratorios y sí de profundizar epistemológicamente sobre las diferentes miradas de un fenómeno que es construido colectivamente.

Por último, el presente texto procura profundizar sobre la influencia del protagonismo empresarial latinoamericano en la propia construcción simbólica de la figura del inmigrante. Tres ejes: provisionalidad, fuerza de trabajo y problema social — que marcan, en general, la condición del inmigrante- son relacionados y cuestionados con el papel que desempeña la propia iniciativa comercial de los latinos en su condición social de inmigrante en España. En lo hondo también se hace referencia de forma indirecta a las formas desiguales de globalizarse, al papel que les toca a unos y otros originarios de países receptores o emisores de migrantes, a las formas de inserción e integración, a la posibilidad de mantener características identitarias particulares, a la mayor o menor tolerancia de la diversidad, más allá de los discursos que señalan la pluralidad de nuestras sociedades modernas.

\section{España como país de destino para los migrantes latinoamericanos}

El número de personas que se desplazan actualmente, ha ganado una proporción tan elevada que algunos autores, como Castles y Miller (1993), llegan a sugerir que vivimos en la era de las migraciones. Además, los movimientos migratorios internacionales se insertan paralelamente a los grandes cambios mundiales. Un fenómeno dinámico y rápido que es capaz de hacer que países caracterizados por la inmigración pasen, en dos décadas, a ser países exportadores de mano de obra o viceversa. Éste es el caso de muchos países latinoamericanos y de España, aunque se sitúan en trayectorias bien distintas.

Así, durante el transcurso de las tres últimas décadas, las sociedades latinoamericanas han contemplado el paso de ser países receptores de inmigrantes a convertirse en emisores. Mientras tanto, en el contexto español, el cambio se ha procesado a la inversa: desde mediados de los años ochenta, España 
ha sido testigo de la llegada de inmigrantes, que, poco a poco, se han ido convirtiendo en una parte de la vida cotidiana.

Además, según Solé (2001), la ubicación de España como destino de diversos colectivos de inmigrantes refleja un desarrollo, en el plano político, social y económico, suficiente como para atraer poblaciones que experimentan realidades bien distintas en sus sociedades de origen. Asimismo, la configuración de España como miembro de la Unión Europea y el afianzamiento de su nueva posición geopolítica promueve una afluencia mayor y cada vez más creciente de inmigrantes procedentes fundamentalmente de África, América Latina y de la llamada Europa del Este, que consolidan la imagen de este país como receptor de extranjeros no comunitarios. A su vez, la coloca en posición semejante al conjunto de países receptores de inmigrantes. Entre los diversos colectivos extracomunitarios residentes en España, paulatinamente, los latinoamericanos empiezan a formar parte del tejido de la inmigración en este país.

Así, la continua demanda de mano de obra para sectores vitales de la economía — como, por ejemplo, la construcción, la agricultura, la hostelería—, el progresivo desarrollo económico, la diversificación del mercado laboral y la baja tasa de natalidad, son algunos de los elementos que convierten a España en un país atractivo para diversos flujos migratorios (Pajares, 1998; Arango, 1999; Solé e Izquierdo, 2006).

Por otro lado, mientras en los años ochenta España comienza el proceso de convertirse en un país de inmigración, muchos países latinoamericanos inician el camino inverso. Si, hasta la década de los años sesenta, estos países estaban marcados por el fenómeno de la inmigración, es a partir de la década de los ochenta cuando se evidencia una modificación en la dinámica de las migraciones internacionales, y pasan, en pocos años, de ser países de inmigración a establecerse como países de emigrantes ${ }^{1}$.

Este cambio en la realidad migratoria, tanto de muchos países latinoamericanos como de España, procesado de modo coetáneo, se debe, según García Cancline (1990), en parte al hecho de que, en las últimas décadas del siglo XX, el mundo contempla transformaciones en diversos campos provocadas por el proceso de globalización.

Además, los desplazamientos de latinoamericanos como trabajadores inmigrantes surgen en un contexto internacional, en que los efectos de la dinámica del capitalismo, caracterizado por la globalización de la producción — con la sucesiva flexibilización de los procesos de trabajo y de los mercados- han generado, de acuerdo con Castells (1997), una creciente desigualdad económica y social.

Para Portes (1995), los flujos migratorios que suponen la entrada de Latinoamérica en el escenario internacional como países emisores de emi-

1. Esto no significa desconocer que, en Latinoamérica, ya había emigraciones específicas en el transcurso del siglo XX y que continúa existiendo, tanto una migración interna, como la presencia de colectivos extranjeros específicos, cuya incidencia demográfica y sociocultural es muy limitada actualmente. 
grantes, se orientan principalmente hacia los Estados Unidos, Japón ${ }^{2}$ y Europa ${ }^{3}$. A partir de la segunda mitad del siglo XX, y más precisamente en el decenio de los años ochenta, la emigración latinoamericana aumenta en densidad y número. Este periodo es conocido, en América Latina, como «la década perdida", expresión muy utilizada por los economistas latinoamericanos para caracterizar la década de 1980 como una etapa en la que se produce un gran descenso de los indicadores económicos, debido a las sucesivas crisis económicas que afectaron a los países latinoamericanos, lo que genera un aumento considerable de la pobreza (Sales, 1998).

Del mismo modo, según García Cancline (2002:19), en los últimos años del siglo XX, la emigración ha sido una realidad tan candente que "América latina no está completa en América latina». A título de ejemplo, el autor observa que, en las últimas décadas, han dejado Uruguay tantas personas como las que nacieron en el país. En Estados Unidos, en Europa o en otras naciones latinoamericanas viven el $15 \%$ de los ecuatorianos. Del mismo modo, el autor afirma que una décima parte de los argentinos, colombianos, cubanos, mexicanos, peruanos y salvadoreños residen actualmente en el extranjero (García Cancline, 2002).

Así, los países latinoamericanos, en general, han pasado de ser receptores de inmigrantes a ser países con un considerable protagonismo de emigración en la actualidad. Sin embargo, esta transición se ha visto acelerada en estos últimos diez años con los diversos procesos económicos y políticos sufridos en estos países, tanto aquéllos procedentes del escenario internacional, como en el contexto interno.

La consolidación de España como país de inmigración, juntamente con la puesta en marcha de políticas restrictivas de inmigración que dificultan la entrada de inmigrantes en los países tradicionalmente receptores de mano de obra extranjera - como es el caso de los Estados Unidos y de algunos países centroeuropeos- aumentan el atractivo de España para las personas procedentes de América Latina. A todo ello se añade el elemento económico, ya que entrar en España puede resultar mucho más barato y menos arriesgado que en otros países, como es el caso de los Estados Unidos.

Además, en el contexto de América Latina, la elección de España también se da por una serie de factores propios de su realidad. Así, los "vínculos históricos» entre España y los países latinoamericanos también aparecen como determinantes en la elección de España como sociedad de destino. Muchos auto-

2. Hay que matizar que la inmigración de latinoamericanos hacia Japón, hasta la actualidad, está formada por un recorte étnico específico, puesto que la mayoría de los inmigrantes son descendientes de japoneses, cuyos padres o abuelos emigraron durante el siglo XX hacía América Latina, sobre todo para Perú, Bolivia y Brasil. Para más datos sobre la inmigración latinoamericana en Japón, consultar los trabajos de Rossini (1992), Kawamura (2002) y Sasaki (1995).

3. No hay que olvidar que sigue habiendo una importante emigración en las regiones fronterizas en América Latina y entre algunos países latinos, como es el caso, por ejemplo, de los peruanos en Argentina o los bolivianos en Brasil, retratados en el trabajo de Silva (1997). 
res como Portes (1995), Sassen (2001), Sayad (1998), entre otros, han insistido en que, tras los flujos migratorios entre países, hay una vinculación que puede ser de distintos órdenes - histórica, política, social, cultural-y que sigue presente y se actualiza en el imaginario de esos países.

En el caso de los latinoamericanos, son muchos los inmigrantes pioneros de las redes migratorias, o los llamados "cabezas de puente» de las cadenas de la inmigración, que afirman que han elegido España por las conexiones culturales e históricas. Además, compartir la lengua, la religión y determinados aspectos culturales también es determinante en la elección del rumbo. Por encima de todo, también se añade el papel que desempeñan las redes migratorias iniciadas o ya consolidadas. La información que transmiten los propios migrantes sobre las condiciones de vida y las posibles dificultades, es decisiva en la posterior elección del país de destino.

\section{La presencia del empresariado latinoamericano en España}

Hasta finales de los años noventa, la actividad emprendedora de los inmigrantes ha sido considerada un tema secundario en España. Tanto la investigación sobre inmigración, como los estudios sobre mercado de trabajo, apenas han abordado este tema. Sin embargo, en el principio de la década actual empiezan a florecer las primeras investigaciones y estudios sobre esta temática, en el contexto específico de distintas comunidades autónomas (Solé y Parella, 2005; Aramburu, 2002; Arjona y Checa, 2004; Cebrian y Bodega, 2002; Moreras, 2002; Oso y Ribas, 2004; Riesco, 2004).

Una gran parte de estos estudios se ha nutrido de otras investigaciones que se han llevado a cabo tanto en Europa, como en Estados Unidos. Según Rath y Kloosterman (2000), la investigación sobre el empresariado inmigrante en estos contextos ha surgido en las últimas décadas del siglo XX y ha estado marcada por el énfasis en las particularidades etnoculturales. Además, la autoocupación de comunidades inmigrantes es visto como un fenómeno especial, con características preindustriales, confinado a lugares inferiores en la escala social, marcado por prácticas ilegales y que estaría condenado a desaparecer.

En España la tendencia que parece haber influenciado algunas investigaciones ha sido precisamente la acentuación en las características etnoculturales de las iniciativas comerciales de los inmigrantes. Así lo demuestra la propia importación del término negocio o empresariado étnico, empleado por una significativa parte de los estudios sobre esta temática.

Ahora bien, si por empresariado étnico entendemos las actividades empresariales realizadas por inmigrantes, en las que hay un conjunto de bienes y servicios de y para una población inmigrada, ¿cómo podemos interpretar las actividades emprendedoras de los latinoamericanos? ¿Se trata realmente de iniciativas comerciales diferentes en sus estrategias de management, en las características de la plantilla, en la clientela, en los productos que se ofrecen? 
Si observamos los comercios regentados por los latinoamericanos en Madrid y Barcelona en relación con el tipo de actividad desarrollada y con la clientela, lo que prevalece es la pluralidad. Lo que más destaca es la multiplicidad de actividades y de consumidores a los que van dirigidos; lo que hace difícil circunscribirlos en bloque dentro del término negocio étnico, si por esto entendemos el suministro de bienes y servicios en el seno de una comunidad étnica, nacional o religiosa.

Por lo general, podemos agrupar las actividades emprendedoras de los latinos en distintas actividades relacionadas con: espacios asociativos (de solidaridad, de deportes, de cooperación internacional, de culto, diversas ONG, entre otros); establecimientos comerciales (alimentación, panaderías, peluquerías, restaurantes, bares, discotecas, empresas de informática, locutorios, artesanías, tiendas de importación y exportación, inmobiliarias, tiendas y talleres de coches, etc.); profesiones liberales (centros de salud, asesoria jurídica, enseñanza, terapias alternativas, diseño y publicidad, informática, artísticas, fiesta y animación, organización de eventos, etc.), y medios de comunicación (radios, periódicos, revistas, imprenta, productora, entre otros).

Según Aramburu (2002), la presencia y la visibilidad de las diversas empresas y emprendimientos de los inmigrantes, en plena expansión en las principales urbes españolas, supone una especie de «anomalía cognitiva» para la imagen preconcebida del inmigrante y contribuyen a crear heterogeneidad al propio modo de concebir al «inmigrante» como una categoría social.

Así, una de las primeras incidencias de estas actividades empresariales en la reconstrucción de la categoría «inmigrante» está relacionada con la propia «revitalización» del espacio geográfico donde estos comercios están localizados. Según Sassen (1997), la instalación de iniciativas comerciales de las comunidades inmigrantes en barrios deprimidos, proporciona un polo de desarrollo económico a través de mercados internos con una demanda y una oferta propias, lo que posibilita un proceso revitalizador (neighborhood upgrading) en dichos barrios o distritos.

Los estudios realizados en las principales ciudades de España coinciden en señalar que la apertura de empresas de inmigrantes en ciudades como Madrid, Barcelona y Valencia, se produce en un contexto de larga crisis del pequeño comercio tradicional de base familiar, que ha sido revitalizado por la reciente presencia de los inmigrantes (Aramburu, 2002; Solé y Parella, 2005; Cebrian y Bodega, 2002).

Del mismo modo, en las zonas de Madrid y Barcelona donde hay más iniciativas comerciales de inmigrantes es justamente en espacios que han sido comercialmente deprimidos en décadas anteriores. Dos barrios que pertenecen al distrito central de ambas ciudades son ejemplos destacados. En Madrid está el barrio de Lavapiés y en Barcelona, el Raval. La presencia de empresas administradas por personas de origen extranjero en estas zonas ha dado lugar a un mayor dinamismo de las actividades comerciales, económicas y sociales, donde se encontraba un alto nivel de degradación. En este sentido, Solé (2004) afirma: 
Todos estos comercios han producido, sin duda, un efecto dinamizador sobre la economía del barrio, especialmente si tenemos en cuenta que, en las últimas dos décadas, la tendencia del comercio en el barrio era la de cerrar sus puertas debido a lo que se ha denominado "crisis del pequeño comercio», fundamentada, según los propios comerciantes, en la competencia de las grandes superficies, la disminución de la población con mayor poder adquisitivo, el incremento constante de impuestos, la falta de relevo generacional, etc. (Solé, 2004: 111-112)

Además de «revitalizar» la zona donde estas actividades se instalan, las iniciativas empresariales de los inmigrantes también desempeña un papel esencial en la reconstrucción de la condición social del inmigrante, aunque no siempre es reconocido como tal. Esto nos lleva a tomar en consideración los riesgos de una posible homogeneización «etnicista» de las diferenciadas iniciativas empresariales de los inmigrantes en España, especialmente de los latinoamericanos.

\section{El empresariado latino y su impacto en la (re)construcción social del inmigrante}

Una de las primeras cuestiones que las actividades empresariales de los latinoamericanos rompen está relacionada con la identificación de la inmigración como un problema social. Como ya ha sido analizado por diferentes autores, la categoría «inmigrante» en España está asociada a un sujeto social representado y construido a través de imágenes asociadas a toda una serie de problemas sociales. A partir de distintos enfoques teóricos y metodológicos, algunos investigadores han demostrado como, en el contexto español, la inmigración y el inmigrante son relacionados con diversos problemas sociales (Santamaría, 2002; Van Dijk, 1997; San Roman, 1997).

De este modo, los originarios del llamado Tercer Mundo que viven en el territorio español son considerados unos de los actores responsables de los principales problemas que preocupan a la población. El paro, el aumento de la inseguridad, la disminución de los servicios sociales, la escasez de la vivien$\mathrm{da}$, entre otras cuestiones - que también preocupan al llamado Primer Mundo-, son, en muchas ocasiones, atribuidas a la "excesiva» presencia de los inmigrantes (Stolcke, 1995).

Así, la práctica discursiva ${ }^{4}$ en relación con el inmigrante está dotada de sentidos y de énfasis distintos por parte de las personas autóctonas, según el terreno y el contexto desde el que se hable, y dependiendo de quien emite el juicio o el "prejuicio». Tanto puede ser un discurso fragmentado en categorías nacionales, como uno de carácter genérico, que los incluya a todos. En este contexto, mientras los científicos sociales de las distintas comunidades autó-

4. Sobre las estructuras que predominan en el discurso sobre la inmigración, véanse los trabajos de Van Dijk (1997) y Edstrom (1993). 
nomas de España vienen calificando de «fenómeno» a la inmigración; el discurso político, mediático y de la opinión pública, la clasifica como un "problema" 5 . Esta identificación de la inmigración como un problema ${ }^{6}$, e incluso como un factor que pone en riesgo a la población de destino, favorece que éstos sean adscritos a una sucesión permanente de "problemas sociales», con lo que, para Van Dijk (1997), se fortalece la idea perversa de que, allá donde hay inmigrantes, existen graves "problemas» de esta naturaleza.

Así, esta representación promueve sentimientos de incomodidad, inseguridad o miedo con respecto a dicho colectivo. El calificativo de "problema» para definir al fenómeno de la inmigración, presentándolo como una amenaza para la estabilidad social del Estado, así como las continuas medidas sociojurídicas y administrativas que limitan la ciudadanía del inmigrante, los crecientes discursos que exaltan la homogeneidad cultural como condición del ideal de convivencia social, se traducen para Stolcke (1995) en una nueva retórica de la exclusión en Europa, en que:

La opinión ciudadana europea culpa cada vez más a los inmigrantes, que no tienen «nuestra» moral y nuestros valores culturales, de todas las desgracias socioeconómicas producto de la recesión y de los reajustes capitalistas (el desempleo, la escasez de vivienda, el incremento de la delincuencia, las deficiencias de los servicios sociales). Los que abogan por detener la inmigración, han logrado incrementar la animosidad popular hacia los inmigrantes exagerando la importancia del «problema». Las alusiones a una «inundación de inmigrantes» y una «bomba de emigración» se utilizan para intensificar unos difusos temores de la población, distrayendo el cada vez mayor descontento social de las verdaderas causas de la recesión económica (Stolcke, 1995: 2)

El tratamiento discursivo sobre los inmigrantes está constantemente asociado a "problemas sociales». Sin embargo, la diversificada presencia del empresariado inmigrante, sus experiencias de vida diferenciadas y las diferentes contribuciones de estos inmigrantes en el campo de la cultura y de la economía, viene creando una «anomalía» a la idea de «inmigrante» como problema social.

Como personas que regentan diversas actividades emprendedoras, los inmigrantes empresarios, con su propia actividad, permiten cuestionar el «discur-

5. Al referirse a la opinión pública, a los medios de comunicación y al universo político, el texto no pretente asumir una actitud generalizadora, ni tampoco afirmar que todos los españoles tienen actitudes xenófobas frente al inmigrante. En España, existe también un debate coherente, que se propone «historizar» la inmigración y reflexionarla de modo integral, además de los más de cuatro millones de españoles que participan activamente como voluntarios en instituciones que trabajan, entre otras cosas, directamente con los inmigrantes. Asumir una visión generalizadora sería caer en una actitud prejuiciosa con la academia y con una significativa parcela del pueblo español.

6. Los barómetros de opinión del Centro de Investigaciones Sociológicas, CIS, revelan que la inmigración, desde hace unos años, viene manteniéndose entre los tres principales "problemas» para los españoles, al lado de cuestiones como el paro, la inseguridad o el terrorismo. Véase http://www.cis.es/bd_estudios.asp?tema=23, acceso el 29 de noviembre de 2005. 
so impuesto» ${ }^{7}$ de la inmigración como un problema social. A todo ello se añade el elemento económico, ya que la aportación a la seguridad social por los inmigrantes empresarios es un ingreso importante e, incluso, valorado por determinados sectores del poder político. Los siguientes relatos aclaran mejor las cuestiones presentadas ${ }^{8}$ :

Mucha gente dice que los inmigrantes son delincuentes, ladrones, que hacen cosas sucias y un montón de barbaridades. Pero todo esto es mentira. Si hay gente que hace eso, son muy poquitos, una minoría. La mayoría de los inmigrantes son gente honrada que trabajan y están ayudando a crear riquezas en este país. Creo que, sinceramente, España debía estar contenta y agradecer la presencia de los inmigrantes. Porque nosotros estamos desarrollando este país con nuestra aportación económica y cultural. (M. 32 años, Ecuador)

Todos nosotros latinos que estamos creando empresas y empleando a trabajadores también somos los principales responsables de que la economía de España esté progresando. Somos todo lo contrario de lo que mucha gente habla. Porque aquí hay muchos ignorantes que hablan que los inmigrantes son ruidosos, atrasados, ladrones, vagabundos y otras barbaridades más. Pero somos nosotros que estamos desarrollando España. Sin los inmigrantes, ¿`ómo tu piensas que se pagaría la jubilación de tanta gente? Además, también aportamos cultura, con nuestra comida, nuestra música..., pero todo lo bueno de los inmigrantes no se muestra, solamente lo malo. Esto es injusto. (C. 39 años, Perú)

Otra cuestión que el empresariado inmigrante pone de relieve está relacionada con la idea de provisionalidad y de fuerza de trabajo que también marcan la condición social del inmigrante.

La condición transitoria del inmigrante no aparece reflejada únicamente en la propia denominación del término «inmigrante» (participio de presente), sino que se observa en ambas sociedades, de emigración e inmigración, en la que le es otorgado un carácter provisional a su condición, que es sostenido, más allá de su permanencia de hecho y/o de derecho (Cavalcanti y Boggio, 2004).

Así, podemos pensar que, en ambas sociedades involucradas en el proceso de la migración, se tolera la consecución del proyecto migratorio bajo la perspectiva de que éste sea definitivamente provisorio, y que su carácter definitivo no sea reconocido como tal. Esta percepción de provisionalidad es alimentada, en la sociedad de inmigración, por el tratamiento jurídico que recibe, lo cual se ve reflejado tanto en los permisos de trabajo y residencia que tienen una validez limitada de tiempo, como también en la posibilidad de expulsión inmediata para los que no gozan de dichos permisos. Por otro lado, en la sociedad de emigración se admite su ausencia a cambio de conservar su presencia, a partir de mantener la provisionalidad duradera de su emigración.

7. Para conocer con detalle el concepto de «discurso impuesto» en el ámbito de los estudios migratorios, consultar Sayad, 1998.

8. Todos los relatos de los inmigrantes citados son del trabajo de campo cuantitativo llevado a cabo en las ciudades de Madrid y Barcelona en el año 2006. 
De este modo, su propia condición constituye un estado ambiguo que oscila entre la transitoriedad que le es atribuida y lo permanente de su proyecto migratorio. Esta doble condición que atraviesa, en general, los procesos migratorios contemporáneos, impele al inmigrante a la dificultad de convivir y actuar en concordancia con este doble estado. De esta forma, se le exige que, en su vida cotidiana, cumpla con lo que se espera de una persona que se encuentra integrada permanentemente a la sociedad; a la vez que, tanto socialmente como de derecho, es portador de la desconfianza que emerge de su supuesta provisionalidad. Aquí reside la paradoja de que el inmigrante deba «integrarse» de forma cada vez más duradera, bajo el reconocimiento provisorio de su condición.

Por otro lado, de acuerdo con Sayad (1998), un inmigrante es esencialmente una fuerza de trabajo - ya que es el trabajo el que da «nacimiento» al mismo, el que lo hace existir, la razón por la que es justificada su estadía o, por el contrario, la que determina su «muerte»- Entonces, en tanto fuerza de trabajo, ésta es provisoria, temporaria, en tránsito, además de la idea que los inmigrantes quitan los puestos de trabajo de los autóctonos.

Sin embargo, esta condición de fuerza de trabajo y de ser provisorio está continuamente cuestionada por los emprendimientos y los comercios de los inmigrantes. Estos establecimientos no solamente dinamizan la economía, sino que son potenciales empleadores y generadores de trabajo. En muchas iniciativas empresariales de los inmigrantes latinos, hay registros de microempresas que tienen la capacidad de generar muchos empleos directos y algunos cuantos indirectos. Así podemos comprobarlo en el siguiente fragmento, en el que uno de los informantes relata la capacidad de su empresa de crear puestos de trabajo:

Cuando llegué a España, pasé muy duro, incluso he dormido en la calle [...] pero, poco a poco, he ido juntando dinero y montando mi negocio. Hoy mi empresa tiene 82 empleados, en que la mayoría son españoles. Yo, un «sudaca», como algunos ignorantes nos llaman a los latinoamericanos, doy de comer a mucha gente de este país. Muchas familias dependen del sueldo de mi empresa. Y no estoy hablando de los empleos indirectos, te estoy hablando de los trabajadores que tienen contrato directo con mi empresa. Y no soy sólo yo, hay muchos paisanos y otros latinos e inmigrantes en general que están dando trabajos a muchos españoles y mismo aquéllos que no tienen empresa, de un modo u otro también son muy importantes, porque contribuyen para la seguridad social y están pagando la jubilación de mucha gente que, sin el dinero de los inmigrantes, sería muy difícil poder pagar las prestaciones a tanta gente. (P. 42 años, Colombia)

La presencia emprendedora de los inmigrantes ha venido debilitando la idea del inmigrante como un ser exclusivamente destinado a servir como mano de obra en el país de recepción. Cuando los inmigrantes ejercen la función de empresarios, además de impulsar la economía - en un sistema que depende de las pequeñas empresas para que el Estado de bienestar social pueda ser fortalecido-, pasan a asumir un papel de protagonistas en la escena pública y económica de la sociedad de recepción. 
Asimismo, esas iniciativas empresariales también relativizan la condición provisoria que es impuesta al inmigrante. La idea de pensar un proyecto empresarial está mucho más distante de la perspectiva de un retorno como un acontecimiento unilineal o una migración de regreso. Al contrario, el empresario inmigrante está más cerca de la posibilidad de permanecer indefinidamente en la sociedad de inmigración, como afirma un inmigrante propietario de una microempresa en Madrid:

Si yo estuviera pensando en volver a mi país de origen, no hubiera arriesgado en abrir una empresa y montar mi propio negocio. Ha sido muy difícil juntar dinero durante varios años, conseguir un crédito, organizar todos los papeles de la empresa, etc. Si he logrado todo este esfuerzo, es porque yo tengo confianza en el sistema económico de España y no pienso en regresar definitivamente a mi país, apenas quiero volver de vacaciones o para visitar algunos amigos o familiares. Yo quiero vivir lo que queda de mi vida aquí y que mis hijos puedan estudiar y tener oportunidades que yo no he tenido... Cuando una persona abre una empresa, está pensando en quedarse, porque, de lo contrario, estaría trabajando por cuenta ajena, ahorrando dinero para volver, pero cuando uno abre una empresa es porque ya hace parte de esta sociedad y quiere quedarse. (J. 36 años, Bolivia)

Por otro lado, la amplia diversidad y los diferenciados tipos de iniciativas comerciales y emprendimientos regentados por los inmigrantes latinos, imposibilitan cualquier intento de encasillar estas actividades dentro de un recorte específico, sea étnico, económico o nacional. Se trata de productos y servicios que son consumidos por inmigrantes del mismo grupo nacional, por otros inmigrantes, por autóctonos y por extranjeros en general.

En suma, el emprendimiento de los inmigrantes cuestiona la propia condición social del «inmigrante» genérico, asociado a toda una serie de problemas sociales, provisionalidad y fuerza de trabajo; del mismo modo que aportan nuevas imágenes al complejo fenómeno contemporáneo de la inmigración extracomunitaria en España.

\section{Conclusión}

La palabra «conclusión», en su sentido etimológico, nos remite al concepto de finalización o fin de un proceso, lo que indicaría que, después de las páginas que siguen, ya no habría lugar para continuar escribiendo. Sin embargo, cuando la labor se refiere a una investigación social, que abarca un fenómeno tan complejo como el de las migraciones internacionales, la palabra "conclusión" - en sentido estricto- quedaría vacía de significado. Esto sucede precisamente por la obvia razón de que cualquier trabajo que se proponga la compleja tarea de pensar el ser humano, en tanto sujeto participante de un universo social urbano, no quedaría acabado al final de ninguna reflexión, sino que más bien evocaría a otras indagaciones que llevarían a nuevas argumentaciones. En este sentido, la «conclusión» nos permite adentrarnos en la reflexión, en el diálogo y 
en la confrontación, en lo relativo a dicho fenómeno y, en concreto, al caso del empresariado latinoamericano en Barcelona y Madrid.

Sin lugar a dudas, el análisis del fenómeno migratorio requiere de un marco teórico que considere las relaciones entre ambas sociedades involucradas en el proceso migratorio. En este sentido, Sayad (1998) — desde una perspectiva dialéctica - subraya la necesidad de pensar las migraciones como «un hecho social total» que envuelve tanto su dimensión diacrónica, es decir, dentro de un marco histórico, como también sincrónica, o sea, enmarcada en las estructuras que están presentes en la sociedad de emigración y de inmigración. Al contemplar esa doble mirada, y en la consideración de sus dimensiones social, política, económica, cultural, entre otras, es posible profundizar en la comprensión de la experiencia migratoria y, en particular, en lo que respecta a la temática del empresariado latinoamericano en España.

Se trata, por tanto, de un hecho colectivo que obedece a las configuraciones macroestructurales, así como a aquéllas compuestas por los itinerarios de orden personal que se forman a través de la trayectoria y la experiencia singular del emigrante-inmigrante. Como hecho social total, la migración está formada por desplazamientos de personas en el espacio, ante todo en un espacio geográfico, pero también — en otros sentidos- en espacios como puede ser el social, el político, el económico o el cultural, por mencionar algunos.

Es cierto que, dadas las condiciones actuales de los lugares de origen y destino, hablar de inmigración y empresariado es casi un pleonasmo, puesto que el propio proyecto migratorio internacional ya se traduce como un evento emprendedor y como una empresa que muy pocos consiguen lograr. Sin embargo, a tenor de las diferentes razones que esgrimen los inmigrantes para convertirse en empresarios, establecer un negocio en la sociedad de inmigración proporciona procesos de movilidad social ascendente y aporta herramientas suficientes para cuestionar la condición social del inmigrante.

En este sentido, estas diferenciadas iniciativas de los migrantes latinoamericanos debilitan la imagen del «inmigrante» como una categoría social fundada a través de imágenes de pobreza, marginalidad y delincuencia. El triangulo formado por provisionalidad, fuerza de trabajo y problema social, viene siendo cuestionado por la propia práctica del empresariado inmigrante que permite también indagar sobre la construcción del inmigrante como una categoría social.

Asimismo, las empresas de los inmigrantes crean relaciones más horizontales con los denominados "autóctonos» y proporcionan movilidad social de sus familiares también en los países de origen, mediante el envío permanente de las remesas. Además del capital económico que estas iniciativas comerciales generan, en ambos países, a través de inversión y creación de puestos de trabajo, también forjan capital social y cultural.

Se ha de decir que si, por un lado, estas diversificadas actividades de los migrantes latinoamericanos rompen con la idea del «inmigrante» como un problema social, fuerza de trabajo y provisionalidad, por otro lado, empiezan a surgir una serie de procedimientos discursivos que normalmente les encasilla en roles y perfiles que etnicizan de manera homogeneizadora la propia heteroge- 
neidad latinoamericana. Esa injusta homogeneización señala una posible formación de nuevas formas de relaciones asimétricas, jerarquizadas y desiguales.

En definitiva, las actividades empresariales de los inmigrantes también permiten plantear una discusión sobre como convive y coexiste al mismo tiempo un discurso basado en una concepción "esencialista» de las actividades empresariales latinoamericanas, con una noción "procesual» de la misma.

Por último, es importante ratificar que se hace necesario seguir estudiando este fenómeno a lo largo del tiempo para acompañar su evolución en la sociedad de inmigración. En cualquier caso, los resultados del trabajo de campo - que está todavía en curso- proporcionarán elementos para conocer el potencial de las iniciativas empresariales de los inmigrantes en generar poder económico y político, al mismo tiempo que proporcionará elementos para comprobar los efectos de la presencia comercial de los latinoamericanos en la (re)construcción social de la categoría «inmigrante» en España.

\section{Bibliografía}

Aramburu, M. (2002). "Los comercios de inmigrantes extranjeros en Barcelona y la recomposición del "inmigrante" como categoría social». Scripta Nova: Revista electrónica de geografia y ciencias sociales, $\mathrm{n}^{\circ}$ 108, <http://www.ub.es/geocrit/sn/sn-108.htm>.

ARANGO, J. (2000). «Enfoques conceptuales y teóricos para explicar la migración». Revista Internacional de Ciencias Sociales, 165: 33-47.

ArJONA, A.; CHECA, J. C. (2004). El empresariado étnico como alternativa a la discriminación laboral: la situación en Almería. Ponencia presentada en el VIII Congreso Español de Sociología, Alicante, 23-25 de septiembre de 2004.

CASTELLS, M. (1997). La era de la información. Vol. 1: La sociedad-red. Madrid: Alianza Editorial.

CASTLES, S.; Miller, M. J. (eds.) (1993). The age of migration international population movements on the modern world. Houndmills: Macmillan.

CAVALCANTI, L.; BOGGIO, K. (2004). Una presencia ausente en espacios transnacionales. Un análisis a partir del cotidiano de uruguayos y brasileños en España. Ponencia presentada en el IV Congreso sobre la inmigración en España. Ciudadanía y participación, celebrado en Girona del 10 al 13 de noviembre del 2004.

Cebrián, J. A.; BODEGA, M. I. (2002). «El negocio étnico, nueva fórmula de comercio en el casco antiguo de Madrid. El caso de Lavapiés». Estudios Geográficos, LXIII, 248/249, p. 559-580.

EVANS-PRITCHARD, E. E. (1978). Os Nuer: Uma descriçao do modo de substância e das instituiçoes políticas de um povo nilota. Sao Paulo: Perspectiva.

DA MATTA, R. (1987). Relativizando. Uma introduçao à antropología social. Rio de Janeiro: Editora Rocco.

GARCÍA CANCLINI, N. (1990). Culturas híbridas: estrategias para entrar y salir de la modernidad. México: Grijalbo.

- (1995). Consumidores y ciudadanos: conflictos multiculturales de la globalización. México: Grijalbo.

- (2002). Latinoamericanos buscando lugar en este siglo. Buenos Aires: Paidós.

IZQUIERDO, A. (2003). Inmigración: Mercado de trabajo y proteccion social en España. Madrid: Consejo Económico y Social. 
LÉVI-STRauss, C. (1970). O pensamento selvagem. Sao Paulo: Cia Editora Naciona e Ed da USP.

MASSEY, D. (1998). Worlds in Motion: Understanding International Migration at the end of the millenium. Oxford: Clarendon Press.

Margolis, M. (1994). Little Brazil: Imigrantes brasileiros em Nova York. Campinas: Papirus.

MORERAS, J. (2002). Les activitats comercials dels estrangers a Ciutat Vella. Barcelona: Fundació CIDOB.

OsO, L.; RIBAS, N. (2004). Empresariado étnico y género: dominicanas y marroquies en Madrid y Barcelona. Ponencia presentada en el IV Congreso Español de la Inmigración en España, Girona, 10-13 de noviembre de 2004.

PAJARES, M. (1998). La inmigración en España. Barcelona: Icària.

PORTES, A. (1995). En torno a la informalidad, ensayos sobre teoría y medición de la economía no regulada. México: Facultad Latinoamericana de Ciencias Sociales.

Rath, J.; Kloosterman, R. (2000). «Outsider's Business. A critical Review on Immigrant Enterpreneurship». International Migration Review, 34(3): 656-680.

RIESCO, A. (2004). Enclaves étnicos, economías étnicas y relaciones salariales. Ponencia presentada en el VIII Congreso Español de Sociología, Alicante, 23-25 de septiembre de 2004.

SALES, T. (1992). «Imigrantes estrangeiros, imigrantes brasileiros: uma revisão bibliográfica e algumas anotações para pesquisa». Revista Brasileira de Estudos Populacionais, Campinas, 9: 22-45.

SANTAMARÍA, E. (2002). La incógnita del extraño: Una aproximación a la significación sociológica de la inmigración no comunitaria. Barcelona: Anthropos.

SAN ROMÁN, T. (1996). Los muros de la separación: Ensayo sobre alterofobia y filantropía. Barcelona: Tecnos.

SASSEN, S. (2001). The global city. New Jersey: Princeton University Press.

- (1997). "Ethnicity in the global city: a new frontier». En: DELGADO, M. (comp.). Ciutat $i$ immigració. Barcelona. Centre de Cultura Contemporània de Barcelona.

SAYAD, A. (1998). A imigração ou os paradoxos da alteridade. São Paulo: Editora da Universidade de São Paulo.

SiLvA, S. (1997). Costurando sonhos. Trajetória de um grupo de imigrantes Bolivianos em São Paulo. São Paulo: Paulinas.

SOlÉ, C. (coord.) (2001). El impacto de la inmigración en la economía y en la sociedad receptora. Barcelona: Anthropos.

SOlÉ, C.; IZQUIERDO, A. (coords.) (2005). Integraciones diferenciadas: migraciones en Cataluña, Galicia y Andalucía. Barcelona: Anthropos Editorial.

Solé, C.; Parella, S. (2005). Los negocios étnicos en Cataluña. Barcelona: Fundació CIDOB.

Solé i Aubia, M.; Rodríguez Roca, J. (2004). «Pakistaníes en España: un estudio basado en el colectivo de la ciudad de Barcelona». Revista CIDOB d'Afers Internacionals. Fundació CIDOB. Barcelona, número 68, p. 97-118.

StOlCKe, V. (1995). «Talking Culture: New Boundaries, New Rhetoric of exclusion in Europe». Currently Anthropology Review, 36, 1-24.

VAN DijK, T. A. (1997). Racismo y análisis crítico de los medios. Buenos Aires: Paidós. 